\title{
Hydrogen Storage: Thermochemical Studies of N-Alkylcarbazoles and their Derivatives as a Potential Liquid Organic Hydrogen Carriers
}

Vladimir N. Emel'yanenko, ${ }^{a}$ Mikhail A. Varfolomeev, ${ }^{b}$ Sergey P. Verevkin, ${ }^{\text {a,b, }}{ }^{*}$ Katharina Stark $^{c}{ }^{c}$ Karsten Müller, ${ }^{c}$ Michael Müller, ${ }^{d}$ Andreas Bösmann, ${ }^{d}$ Peter Wasserscheid, ${ }^{d}$ Wolfgang Arlt ${ }^{c}$

${ }^{a}$ Department of Physical Chemistry and Department ,, Science and Technology of Life, Light and Matter", University of Rostock, Dr-Lorenz-Weg 1, D-18059, Rostock, Germany

${ }^{b}$ Department of Physical Chemistry, Kazan Federal University, Kremlevskaya str. 18, 420008 Kazan, Russia

${ }^{c}$ Lehrstuhl für Thermische Verfahrenstechnik der Universität Erlangen Nürnberg, Egerlandstr. 3, 91058 Erlangen, Germany

${ }^{d}$ Lehrstuhl für Chemische Reaktionstechnik der Universität Erlangen Nürnberg, Egerlandstr. 3, 91058 Erlangen, Germany

* To whom correspondence should be addressed, E-mail: sergey.verevkin@uni-rostock.de (S.P. Verevkin) 
Table S1. Formula, Density $\rho(T=298 \mathrm{~K})$, Specific Heat Capacity $\mathrm{c}_{\mathrm{p}}(T=298 \mathrm{~K})$, and Expansion Coefficients $(\delta V / \delta T)_{\mathrm{p}}$ of the Materials Used in the Present Study

\begin{tabular}{|c|c|c|c|c|}
\hline Compounds & Formula & $\frac{\rho}{\mathrm{g} \cdot \mathrm{cm}^{-3}}$ & $\frac{\mathrm{c}_{\mathrm{p}}}{\mathrm{J} \cdot \mathrm{K}^{-1} \cdot \mathrm{g}^{-1}}$ & $\frac{10^{-6} \cdot(\delta V / \delta T)_{p}}{\mathrm{dm}^{3} \cdot \mathrm{K}^{-1}}$ \\
\hline iso-propyl carbazole & $\mathrm{C}_{15} \mathrm{H}_{15} \mathrm{~N}$ & $1.143^{\mathrm{a}}$ & $1.17^{b}$ & 0.1 \\
\hline n-propyl carbazole & $\mathrm{C}_{15} \mathrm{H}_{15} \mathrm{~N}$ & $1.186^{\mathrm{a}}$ & $1.21^{\mathrm{b}}$ & 0.1 \\
\hline n-butyl carbazole & $\mathrm{C}_{16} \mathrm{H}_{17} \mathrm{~N}$ & $1.156^{\mathrm{a}}$ & $1.26^{\mathrm{b}}$ & 0.1 \\
\hline polyethylene $^{\mathrm{c}}$ & $\mathrm{CH}_{1.93}$ & 0.92 & 2.53 & 0.1 \\
\hline $\operatorname{cotton}^{\mathrm{d}^{2}}$ & $\mathrm{CH}_{1.774} \mathrm{O}_{0.887}$ & 1.50 & 1.67 & 0.1 \\
\hline
\end{tabular}

${ }^{\text {a }}$ Measured with pycnometer AccuPyc 1330 Micromerics.

${ }^{\mathrm{b}}$ Calculated using procedure suggested by Chickos and Acree ${ }^{42}$

${ }^{\mathrm{c}}$ Energy of combustion $\Delta_{\mathrm{c}} u^{\circ}$ (polyethylene) $=-46357.3 \mathrm{~J} \cdot \mathrm{g}^{-1} ; u\left(\Delta_{\mathrm{c}} u^{\circ}\right)=3.6 \mathrm{~J} \cdot \mathrm{g}^{-1}$.

${ }^{\mathrm{d}}$ Energy of combustion $\Delta_{\mathrm{c}} u^{\circ}($ cotton $)=-16945.2 \mathrm{~J} \cdot \mathrm{g}^{-1} ; u\left(\Delta_{\mathrm{c}} u^{\circ}\right)=4.2 \mathrm{~J} \cdot \mathrm{g}^{-1}$.

\section{TABLE S2}

Results for Typical Combustion Experiments at $T=298.15 \mathrm{~K}\left(\mathrm{p}^{\circ}=0.1 \mathrm{MPa}\right)$ of the Alkyl Carbazoles $^{\text {a }}$

\begin{tabular}{lccc}
\hline & N-isopropyl-carbazole & N-propyl-carbazole & N-butyl-carbazole \\
\hline$m$ (substance) $/ \mathrm{g}$ & 0.258439 & 0.449900 & 0.312365 \\
$m^{\prime}$ (cotton) $/ \mathrm{g}$ & 0.000994 & 0.000929 & 0.001051 \\
$m^{\prime \prime}($ polyethylene) $/ \mathrm{g}$ & 0.381992 & 0.169338 & 0.294191 \\
$\Delta T_{\mathrm{c}} / \mathrm{K}$ & 1.86101 & 1.69617 & 1.73913 \\
$\left(\varepsilon_{\text {calor }}\right) \cdot\left(-\Delta T_{\mathrm{c}}\right) / \mathrm{J}$ & -27724.7 & -25249.1 & -25888.6 \\
$\left(\varepsilon_{\text {cont }}\right) \cdot\left(-\Delta T_{\mathrm{c}}\right) / \mathrm{J}$ & -30.39 & -28.2 & -27.87 \\
$\Delta U_{\text {decomp }} \mathrm{HNO}_{3} / \mathrm{J}$ & 49.57 & 40.61 & 42.41 \\
$\Delta U_{\text {corr }} / \mathrm{J}$ & 10.79 & 9.2 & 10.46 \\
$-m^{\prime} \cdot \Delta_{\mathrm{c}} u^{\prime} / \mathrm{J}$ & 16.84 & 15.74 & 17.81 \\
$-m^{\prime \prime} \cdot \Delta_{\mathrm{c}} u^{\prime \prime} / \mathrm{J}$ & 17708.12 & 7850.05 & 16637.9 \\
$\Delta_{\mathrm{c}} u^{\circ}($ liq $) /\left(\mathrm{J} \cdot \mathrm{g}^{-1}\right)$ & -38576.9 & -38590.1 & -39082.2 \\
\hline
\end{tabular}

a The definition of the symbols assigned according to ref. [27] as follows: $m$ (substance), $m^{\prime}$ (cotton), and $m$ "(polyethylene) are the mass of compound burnt, the mass of fuse (cotton) and the mass of polyethylene pieces used in each experiment. Masses were corrected for buoyancy using densities listed in table 2. The mass of 2methyl-benzonitrile was corrected with $660.15 \mathrm{ppm}$ of water. The mass of 3-methylbenzonitrile was corrected with $2010.0 \mathrm{ppm}$ of water. $V($ bomb $)=0.32 \mathrm{dm}^{3}$ is the internal volume of the calorimetric bomb; $p^{\mathrm{i}}($ gas $)=3.04$ $\mathrm{MPa}$ is the initial oxygen pressure in the bomb; $m^{\mathrm{i}}\left(\mathrm{H}_{2} \mathrm{O}\right)=1.00 \mathrm{~g}$ is the mass of water added to the bomb for dissolution of combustion gases; $\varepsilon_{\text {calor }}=(14886.0 \pm 1.0) \mathrm{J} \cdot \mathrm{K}^{-1}$ is the energy equivalent of the calorimeter; $\Delta T_{\mathrm{c}}=$ $T^{\mathrm{f}}-T^{\mathrm{i}}+\Delta T_{\text {corr }}$ is the corrected temperature rise from initial temperature $T^{\mathrm{i}}$ to final temperature $T^{\mathrm{f}}$, with the correction $\Delta T_{\text {corr }}$ for heat exchange during the experiment; $\varepsilon_{\text {cont }}$ is the energy equivalents of the bomb contents in their initial $\varepsilon_{\text {cont }}^{\mathrm{i}}$ and final states $\varepsilon_{\text {cont }}^{\mathrm{f}}$, the contribution for the bomb content is calculated with $\left(\varepsilon_{\text {cont }}\right) \cdot(-$ $\left.\Delta T_{\mathrm{c}}\right)=\left(\varepsilon_{\text {cont }}^{\mathrm{i}}\right) \cdot\left(T^{\mathrm{i}}-298.15\right)+\left(\varepsilon_{\text {cont }}^{\mathrm{f}}\right) \cdot\left(298.15-T^{\mathrm{f}}+\Delta T_{\text {corr. }}\right) \cdot \Delta U_{\text {decomp }} \mathrm{HNO}_{3}$ is the energy correction for the nitric acid formation. $\Delta U_{\text {corr }}$ is the correction to standard states. 
TABLE S3. Values of Specific Energies of Combustion $-\Delta_{\mathrm{c}} u^{\circ}$ in $\mathbf{J}^{-1}$ at $\boldsymbol{T}=\mathbf{2 9 8 . 1 5} \mathrm{K}$ as the Results of All Combustion Experiments.

\begin{tabular}{llll}
\hline & N-isopropyl-carbazole & N-propyl-carbazole & N-butyl-carbazole \\
\hline & 38576.9 & 38580.7 & 39082.2 \\
& 38606.0 & 38591.9 & 39069.3 \\
& 38600.2 & 38590.1 & 39075.4 \\
& 38602.4 & 38584.8 & 39069.1 \\
$-\Delta_{\mathrm{c}} u^{\circ}(\mathrm{cr}) /\left(\mathrm{J} \cdot \mathrm{g}^{-1}\right)$ & 38606.5 & 38586.0 & 39066.9 \\
$u\left(\Delta_{\mathrm{c}} u^{\circ}\right) / \mathrm{J} \cdot \mathrm{g}^{-1}$ & 38598.4 & 38586.7 & 39072.6 \\
\hline
\end{tabular}

Table S4. Compilation of Data on Molar Heat Capacities (in $\mathrm{J}^{\circ} \mathrm{mol}^{-1} \cdot \mathrm{K}^{-1}$ ) at $298 \mathrm{~K}$ of the Carbazole Derivatives

\begin{tabular}{lllll}
\hline \multicolumn{1}{c}{ Compounds } & $C_{p, m}^{\circ}(\mathrm{cr})^{\mathrm{a}}$ & $-\Delta_{\mathrm{cr}}^{\mathrm{g}} C_{p, m}^{\circ} \mathrm{b}$ & $C_{p, m}^{\circ}(\text { liq })^{\mathrm{a}}$ & $-\Delta_{1}^{\mathrm{g}} C_{p, m}^{\circ} \mathrm{b}$ \\
\hline N-iso-propyl-carbazole & 245.9 & 37.6 & 356.7 & 103.3 \\
N-propyl-carbazole & 254.1 & 38.9 & 363.2 & 105.0 \\
N-butyl-carbazole & 281.0 & 42.9 & 395.1 & 113.3 \\
\hline
\end{tabular}

${ }^{\text {a }}$ Calculated according to procedure developed by Chickos et al. ${ }^{43}$

${ }^{\mathrm{b}}$ Calculated according to procedure developed by Chickos and Acree ${ }^{42}$ 


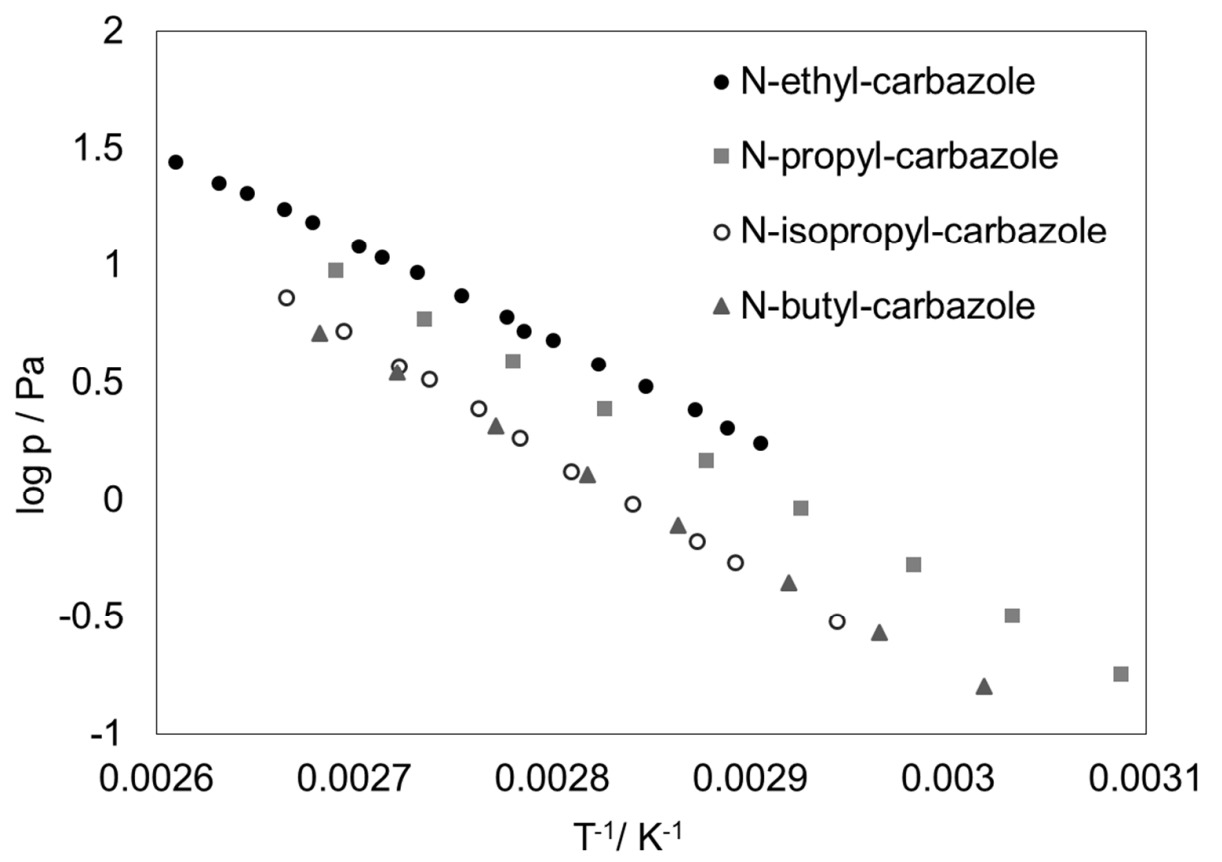

Figure S1. Comparison of vapor pressures of the carbazole derivatives (data N-ethylcarbazole from ref. ${ }^{18}$ )

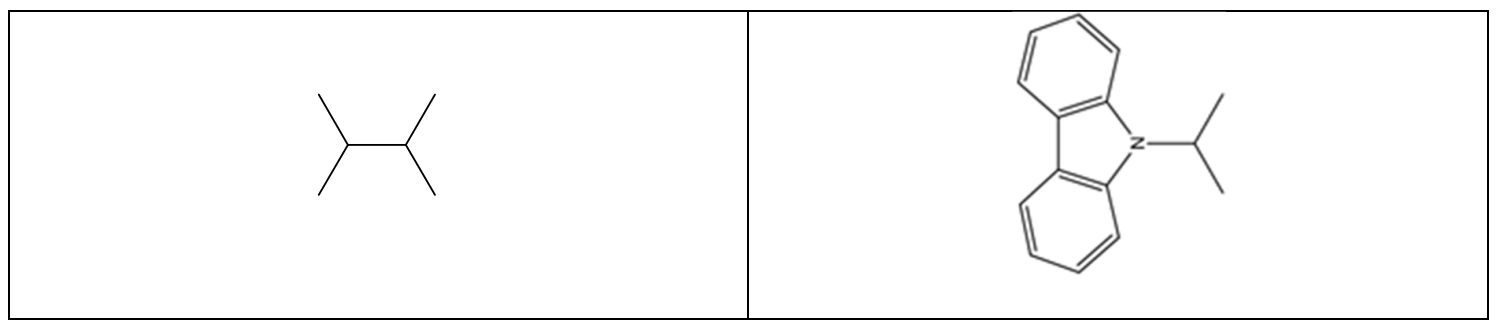

Figure S2. Comparison of strain patterns in 2,3-dimethylbutane and N-iso-propyl carbazole

Evaluated data for acenaphthene from Roux, M.V.; Temprado, M.; Chickos, J.S.; Nagano, Y., Critically Evaluated Thermochemical Properties of Polycyclic Aromatic Hydrocarbons, $J$. Phys. Chem. Ref. Data, 2008, 37, 1855-1996.

$\Delta_{\mathrm{f}} H_{m}^{\circ}(\mathrm{cr}$, acenaphthene, $298 \mathrm{~K})=72.0 \pm 3.3 \mathrm{~kJ} \cdot \mathrm{mol}^{-1}$

$\Delta_{\mathrm{cr}}^{\mathrm{g}} H_{m}^{\circ}($ acenaphthene, $298 \mathrm{~K})=84.8 \pm 3.3 \mathrm{~kJ} \cdot \mathrm{mol}^{-1}$

$\Delta_{\mathrm{cr}}^{1} H_{m}^{\circ}($ acenaphthene, $298 \mathrm{~K})=18.4 \pm 1.1 \mathrm{~kJ} \cdot \mathrm{mol}^{-1}$

From this data $\Delta_{\mathrm{f}} H_{m}^{\circ}($ liq, acenaphthene, $298 \mathrm{~K})=90.4 \pm 3.3 \mathrm{~kJ} \cdot \mathrm{mol}^{-1}$ 
Gas-phase molar enthalpy of hydrogenation of acenaphthene to perhydroacenaphthylene:

$$
\mathrm{C}_{12} \mathrm{H}_{10}(\mathrm{~g})+6 \mathrm{H}_{2}(\mathrm{~g})=\mathrm{C}_{12} \mathrm{H}_{20}(\mathrm{~g}) \text { with } \Delta_{\mathrm{r}} H_{m}^{\circ}(\mathrm{g})=-77.8 \pm 3.8 \mathrm{~kJ} \cdot \mathrm{mol}^{-1}
$$

Calculated from the experimental temperature dependence of equilibrium constants reported in Frye, C.G.; Weitkamp, A.W., Equilibrium hydrogenations of multi-ring aromatics, $J$. Chem. Eng. Data, 1969, 14, 372-376.

This reaction enthalpy together with the value $\Delta_{\mathrm{f}} H_{m}^{\circ}$ (liq, acenaphthene, $\left.298 \mathrm{~K}\right)=90.4 \pm 3.3$ $\mathrm{kJ} \cdot \mathrm{mol}^{-1}$ we used to calculate $\Delta_{\mathrm{f}} H_{m}^{\circ}($ liq, perhydroacenaphthene, $298 \mathrm{~K})=38 \mathrm{~kJ} \cdot \mathrm{mol}^{-1}$, provided that the vaporization enthalpy of perhydroacenaphthene amounts $\Delta_{1}^{\mathrm{g}} H_{m}^{\circ}$ (perhydro acenaphthene, $298 \mathrm{~K})=41 \mathrm{~kJ} \cdot \mathrm{mol}^{-1}$ as estimated using the group-contributions listed in Table 7.

All these calculations lead to the reaction enthalpy of hydrogenation of acenaphthene to perhydroacenaphthylene in the liquid phase:

$$
\mathrm{C}_{12} \mathrm{H}_{10} \text { (liq) }+6 \mathrm{H}_{2}(\mathrm{~g})=\mathrm{C}_{12} \mathrm{H}_{20} \text { (liq) with } \Delta_{\mathrm{r}} H_{m}^{\circ}=-52.4 \mathrm{~kJ} \cdot \mathrm{mol}^{-1}
$$

Which is now comparable with the data represented by reactions 11-13. 